\title{
Tumor neuroectodérmico primitivo da bexiga urinária: uma rara neoplasia
}

\author{
Primitive neuroectodermal tumor of the urinary bladder: a rare neoplasm
}

Daniel Cury Ogata'; Elisiário Pereira Neto²; Wilson F. Schreider Busato Júnior³; Dayane Regina Gusso4

unitermos

Tumor neuroectodérmico primitivo

Bexiga urinária

\section{resumo}

Os autores relatam o caso de paciente do sexo feminino, 52 anos, com queixas de hematúria macroscópica e dor pélvica. Foi realizado exame ultrassonográfico, que mostrou massa expansiva em assoalho vesical. A cistoscopia confirmou a presença dessa lesão, sendo realizada biópsia. O exame histológico revelou neoplasia de pequenas células. A análise imuno-histoquímica foi necessária para elucidação diagnóstica. O referido exame demonstrou positividade para os marcadores EWS-FLI1, CD99 e S-100. O diagnóstico foi de tumor neuroectodérmico primitivo. A paciente foi tratada com quimioterapia adjuvante. Depois de sete meses de seguimento, a paciente encontra-se livre de doença.

\section{abstract}

The authors report the case of a 52 year-old woman that presented macroscopic hematuria and pelvic pain. Ultrasound examination was performed, which showed an expansive mass in the bladder floor. A cystoscopy confirmed the presence of this lesion and a biopsy was carried out. Histological analysis showed a small cell neoplasm. The immunohistochemical analysis was required to establish diagnosis. This analysis revealed positivity for EWS-FLI1, CD99 and S-100. The conclusive diagnosis was primitive neuroectodermal tumor. The patient was treated with chemotherapy. After a seven month follow-up period, the patient is disease-free. 


\section{Introdução}

O conceito de tumor neuroectodérmico primitivo (PNET) foi descrito inicialmente em 1918 e compreende um grupo de neoplasias malignas de pequenas células com ampla distribuição(5). O PNET é considerado membro da família dos tumores de Ewing, sendo que o sarcoma de Ewing é a forma menos diferenciada do PNET primário(6). Essas neoplasias exibem variável grau de diferenciação neural e originam-se fora do cérebro, da medula espinhal ou do sistema nervoso simpático ${ }^{(6)}$. Em geral, elas acometem partes moles e, menos frequentemente, o sistema esquelético.

O PNET primário da bexiga urinária é excepcionalmente raro, sendo relatados apenas seis casos na literatura mundial( ${ }^{(6)}$. Nós relatamos, aqui, um caso de paciente do sexo feminino, 52 anos, com queixas de hematúria macroscópica e dor pélvica, cujo diagnóstico foi de tumor neuroectodérmico primitivo de bexiga urinária.

\section{Relato de caso}

Paciente do sexo feminino, 52 anos, procurou atendimento médico com queixas de hematúria macroscópica e dor pélvica. Não havia nenhuma alteração nos exames físico e laboratorial. Para melhor esclarecimento diagnóstico, foi realizado exame ultrassonográfico, que mostrou massa expansiva em assoalho vesical. Posteriormente, a paciente foi submetida a uma cistoscopia que confirmou essa lesão, medindo aproximadamente $3 \mathrm{~cm}$ no maior eixo. Optouse por fazer a ressecção dessa massa, encaminhando esse material para estudo histológico.

O referido exame mostrou neoplasia sólida, constituída por células pequenas, com escasso citoplasma, núcleo intensamente hipercromático, apresentando nucléolos inconspícuos. A atividade mitótica era exuberante e havia pequenos focos de necrose. Ocasionalmente foram observadas pseudorrosetas (Figura 1).

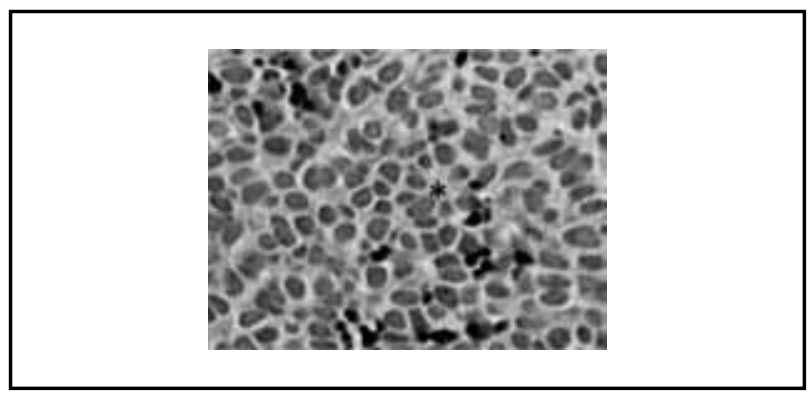

Figura 1 - Neoplasia sólida, constituída por células pequenas, com escasso citoplasma, núcleo hipercromático e nucléolo inconspícuo. Presença de pseudorroseta (*) (HE 400x)
Com base nesses achados, foi necessária a complementação com estudo imuno-histoquímico. O painel desse exame mostrou positividade nuclear para o EWS-FLI1, positividade do tipo membrana para o CD99 (Figura 2) e positividade focal para a proteína S-100. Os demais marcadores, incluindo a cromogranina, foram negativos. Com esses resultados, o diagnóstico conclusivo foi de tumor neuroectodérmico primitivo (PNET) da bexiga urinária.

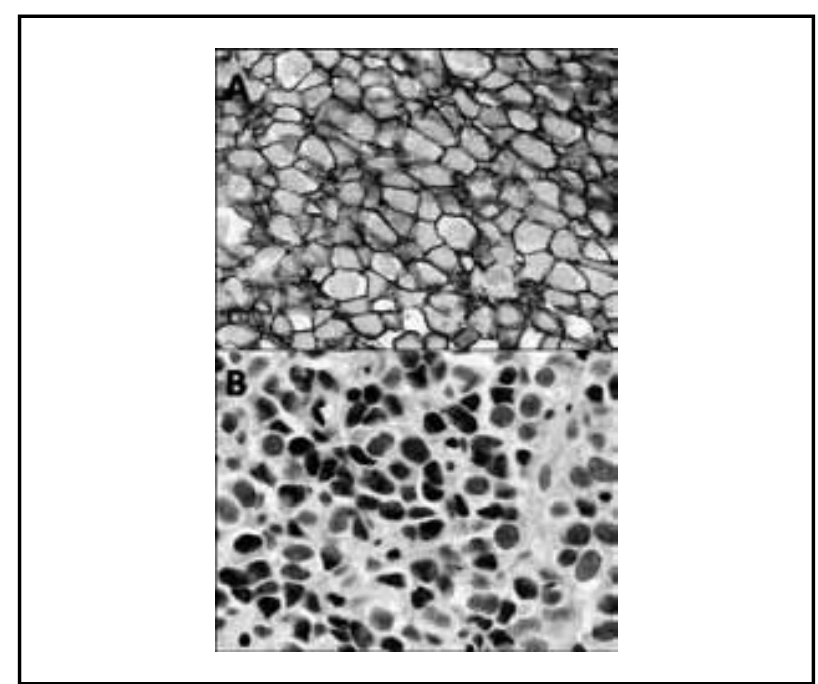

Figura 2 - Exame imunoistoquímico mostrando positividade com padrão membrana para o CD99 (A) (400x) e padrão nuclear para o EWS-FLI1 (B) (400x)

Foram realizados, na sequência, exames de imagem que não revelaram indícios da doença em sítio extravesical. Posteriormente, a paciente foi encaminhada para tratamento adjuvante quimioterápico. Ela, atualmente, encontra-se bem, em seguimento de sete meses, sem sinais de doença residual.

\section{Discussão}

Atualmente os PNETs, também conhecidos como neuroepiteliomas periféricos, são atribuídos como parte da família de tumores relacionados com o sarcoma de Ewing. A estreita relação entre essas neoplasias pode ser demonstrada por achados citogenéticos, ultraestruturais e imuno-histoquímicos em comuns ${ }^{(5)}$.

A média de idade dos pacientes com PNET da bexiga urinária foi de 43 anos, variando de 15 a 81 anos ${ }^{(6,7)}$. Os sintomas mais frequentes desses indivíduos foram disúria, hematúria, linfedema de membros inferiores, fadiga e incontinência urinária( ${ }^{(7)}$. Os PNETs primários 
da bexiga urinária tendem a se disseminar localmente, com envolvimento dos linfonodos regionais ${ }^{(2)}$.

Histologicamente, os tumores da família Ewing são compostos de lençóis celulares sólidos, infiltrando difusamente o estroma submucoso e a camada muscular própria. Essas células têm pouca coesividade e escasso citoplasma, contendo variável quantidade de glicogênio. O núcleo é altamente pleomórfico, apresentando cromatina finamente dispersa e nucléolo de tamanho variável(5). Os PNETs podem ser diferenciados dos sarcomas de Ewing pela presença de diferenciação neuroepitelial. Os achados neurais manifestam-se pela presença de rosetas de HomerWright e pseudorrosetas, presentes neste relato. As áreas de diferenciação epitelial são evidenciadas pelos lençóis celulares supracitados e ocasionalmente pelas formações glandulares ${ }^{(4,5)}$. A ausência de material fibrilar intercelular exclui a possibilidade de neuroblastoma ${ }^{(4)}$, extremamente infrequente na faixa etária do presente caso.

Como já mencionado, os PNETs guardam similaridades com o sarcoma de Ewing, dividindo, assim, algumas semelhanças nas anormalidades cromossômicas ${ }^{(7)}$. A origem genética dessas neoplasias está fundamentada, principalmente, em uma translocação cromossômica $\mathrm{t}(11 ; 22)$ (q24; q12). Tal situação resulta na fusão entre os genes do locus EWSR1 e outro relacionado com um fator de transcrição, que em $85 \%$ dos casos é o FLI1. O resultado é o gene híbrido EWS-FLI1, que está implicado na patogênese dos tumores da família Ewing(3). A detecção desta translocação tornou-se útil na definição diagnóstica para este grupo de neoplasias ${ }^{8}$. Além da expressão para o EWS-FLI1, observada em $90 \%$ dos PNETs renais ou de bexiga urinária, a imunorreatividade para o CD99 está presente em $100 \%$ dos $\operatorname{casos}^{(1,2,10)}$. Outros anticorpos que mostram positividade nos PNETs são a vimentina e o $C^{2} 117^{(7)}$. A imunopositividade focal para S-100 é observada, bem como a expressão focal para citoqueratinas ( $57 \%$ dos casos) $)^{(7)}$. A evidência de diferenciação neuroectodérmica pode ser demonstrada pela expressão variável dos marcadores sinaptofisina, neurofilamentos, neurônio-enolase específico e cromogranina $^{(2,4)}$.

O padrão morfológico indiferenciado desse grupo de tumores pode mimetizar inúmeras neoplasias, incluindo linfoma linfoblástico, rabdomiossarcoma, tumor desmoplásico de pequenas células (TDPC) e carcinoma neuroendócrino ${ }^{(8)}$. Eventualmente, os PNETs podem mostrar concomitantemente imunopositividade para citoqueratinas e marcadores neuroendócrinos, como a cromogranina. Nessas situações, o diagnóstico diferencial com os carcinomas neuroendócrinos de pequenas células pode ser difícil, devendo haver estudos genéticos ou ultraestruturais adicionais para elucidação histogênica(6). Os demais diagnósticos podem ser excluídos pelo painel imuno-histoquímico, que revela negatividade para marcadores musculares e linfoides, afastando respectivamente o rabdomiossarcoma e o linfoma linfoblástico ${ }^{(6)}$. A falta de diferenciação divergente, caracterizada pela expressão concomitante de marcadores epiteliais, mesenquimais e neurais afasta o diagnóstico de TDPC ${ }^{(9)}$.

Em resumo, os PNETs da bexiga urinária são neoplasias raríssimas, cujo diagnóstico está baseado em achados morfológicos, imuno-histoquímicos e moleculares. Uma vez diagnosticados, o tratamento multimodal está indicado. Apesar de todas as opções terapêuticas disponíveis, o prognóstico, principalmente para as doenças metastáticas, continua sendo desfavorável.

\section{Agradecimentos}

Agradecemos à Consultoria em Patologia Bacchi pelo suporte técnico prestado especificamente na realização deste manuscrito.

\section{Referências}

1. BANERJEE, S. S. et al. Primary peripherical neuroectodermal tumour of urinary bladder. Histopathology, v. 30, n. 5, p. 486-90, 1997.

2. ELLINGER, J. et al. Primitive neuroectodermal tumor: rare, highly aggressive differential diagnosis in urologic malignancies. Urology, v. 68, n. 2, p. 257-62, 2006.

3. KAUER, $M$ et al. A molecular function Map of Ewing's Sarcoma. PLoSOne, v. 4, n. 4, e5415, 2009.

4. KHOURY, J. D. Ewing sarcoma family of tumors. Adv Anat Pathol, v. 12, p. 212-20, 2005. 
5. KRÜGER, S. et al. Primitive neuroectodermal tumor (PNET) of the urinary bladder. Pathol Res Pract, v. 199, p. 751-54, 2003.

6. LOPEZ-BELTRAN, A. etal. Primary primitive neuroectodermal tumour of the urinary bladder: a clinico-pathological study emphasizing immunohistochemical, ultrastrutural and molecular analyses. J Clin Pathol, v. 59, p. 77578, 2006.

7. LOTT, S. et al. Soft tissue tumors of the urinary bladder part II: malignant neoplasm. Hum Pathol, v. 38, p. 963-77, 2007.

8. MHAWECH-FAUCEGLIA, P. et al. Diagnostic utility of FLI-1 monoclonal antibody and dual-colour, break-apart probe fluorescence in situ (FISH) analysis in Ewing's sarcoma/ primitive neuroectodermal tumour (EWS/PNET). A comparative study with CD99 and FLI-1 polyclonal antibodies. Histopatology, v. 49, p. 569-75, 2006.

9. OGATA, D. C. et al. Tumor desmoplásico de pequenas células: relato de um caso de difícil diagnóstico. Revista Brasileira de Cancerologia, v. 51, p. 263-66, 2005.

10. OSONE, S. et al. A case of an Ewing sarcoma family tumor in the urinary bladder after treatment for acute lymphoblastic leukemia. J Pediatr Oncol, v. 29, n. 12, p. 841-44, 2007. 